\title{
Avaliação de Escolas Inscrita no Referencial Técnico-Gestionário e na Narrativa
}

\author{
do Management
}

\section{Evaluation of Schools Inscribed in the Technical-Management Reference and Management Narrative}

\author{
Henrique Ramalho \\ Instituto Politécnico de Viseu - Escola Superior de Educação
}

\begin{abstract}
Resumo
A avaliação externa de escolas, estando inscrita num modelo instituído matizado por nuances mecanomórficas e econométricas, mantém o seu foco num novo gerencialismo educacional. $\mathrm{O}$ ensaio agora apresentado alinha-se com a discussão e construção de uma base analítica e (re)interpretativa dos referentes da avaliação de escolas inscrito nas prerrogativas do referencial técnico gestionário e da respetiva narrativa do management. Tem o objetivo de gerar contributos para a construção de um modelo de análise das lógicas, dinâmicas e principais prerrogativas que tenderão, em maior ou menor grau e em diferentes escalas, a influenciar as arquiteturas dos referenciais da avaliação das escolas.

Palavras-chave: avaliação de escolas, referencial técnico gestionário, narrativa do management.
\end{abstract}

\begin{abstract}
The external evaluation of schools, being inscribed in an established model nuanced by mechanomorphic and econometric nuances, maintains its focus on a new educational management. The essay now presented is aligned with the discussion and construction of an analytical and (re) interpretative basis of the referents of the evaluation of schools inscribed in the prerogatives of the managerial technical reference and of the respective management narrative. It aims to generate contributions for the construction of a model of analysis of the logics, dynamics and main prerogatives that will tend, to a greater or lesser degree and at different scales, to influence the architectures of the schools' evaluation frameworks Keywords: Evaluation of schools, management technical reference, management narrative.
\end{abstract}

\section{Introdução}

A última década, em Portugal, tem sido palco de importantes evoluções no capítulo da avaliação externa de escolas, tendo atravessado dois ciclos planeados a partir da esfera central, na base de uma macrorreferencialização de feição tecnocêntrica. Uma base de referencialização perpassada por vários domínios, desde o planeamento curricular e pedagógico, até às competências de gestão de recursos, de organização e métodos de trabalho a desenvolver, onde se inclui a utilidade de um planeamento estratégico sustentado por práticas de avaliação interna e consequentes planos de ação e melhoria. Assiste-se ao incremento de uma narrativa tendencialmente produtivista e mercantil, em que a avaliação das escolas parece ser submetida aos fatores e índices sintéticos de produtividade, ao cálculo das probabilidades de sucesso escolar e do necessário rendimento que lhe pode e deve ser afeto.

Congruentemente, focalizamo-nos em quatro questões críticas: Qual é a natureza ideológica, política e cultural da arquitetura do referencial da avaliação de escolas em análise? Que tipo de influências são suscetíveis de ser analisadas e compreendidas, ao nível do trabalho escolar, com a institucionalização do referencial de avaliação em causa? Qual o tipo de aprovisionamento e de (re)afetação está a ocorrer ao nível dos recursos humanos educativos, com especial destaque para os professores? O que é que muda em termos de lideranças quando estas são perspetivadas segundo uma lógica que tende a incrementar modelos de gestão, caracteristicamente, mercantis e produtivistas?

Metodologicamente, procedemos a uma análise não sistemática dos discursos e narrativas de natureza concetual e normativa, enquanto eixos de (re)interpretação crítica da arquitetura e pressupostos associados ao processo de referencialização da escola enquanto objeto de avaliação. Pressupõe-se uma análise organizada para estabelecer nexos e (des)articulações analíticas e interpretativas no conhecimento existente sobre o objeto em estudo, onde cumprimos com o propósito de inserir o tema revisto dentro de um quadro de referência teórica polimórfica.

O referencial técnico gestionário e a narrativa do management em discurso oficial

Com a publicação da Lei n. ${ }^{\circ}$ 31/2002, de 20 de dezembro e, mais tarde, com a institucionalização do Programa de Avaliação Externa das Escolas (Portugal, ME - IGE, 2009), desenvolveu-se, em Portugal, a crença generalizada de que as escolas deverão olhar para a avaliação externa como um mecanismo, cuja apropriação/reprodução - mais ou menos mimética - 
potencia processos de melhoria e de estratégia de desenvolvimento alinhados com as promissoras prerrogativas dogmáticas da eficiência, eficácia e qualidade do serviço escolar (cf. art. $^{\circ} 3 .^{\circ}$, $^{\text {art. }}{ }^{\circ} 8 .^{\circ}$, da Lei n. ${ }^{\circ} 31 / 2002$, de 20 de dezembro).

$\mathrm{O}$ facto de se adotar uma abordagem gestionária no processo de referencialização e modelização da avaliação externa das escolas leva a que tais processos passem a ser caracterizados por uma narrativa exprimida pelas práticas do management e de tudo o que encerra ao nível do funcionamento e utilidade económica do sistema educativo, das escolas e dos docentes. Também por isso denuncia-se, em primeira instância, a escola como contexto privilegiado de justificação da utilidade da avaliação externa e, portanto, como principal unidade de análise de si própria (ME - IGE, 2009) e, consequentemente, do Sistema.

Nesse caso, o significado dos domínios e indicadores de avaliação, estando explicitados num quadro de referência de feição tecnocêntrico, (Portugal, ME - IGE, 2009, p. 8) tendem a estar submetidos a um ideário neogerencialista que adiante exploraremos com mais afinco. Por agora, aventamos a focalização das práticas escolares na gestão eficientista dos processos subsidiários ditos críticos da gestão escolar, que se pretende concretizar na senda de um essencialismo das práticas de gestão especialmente vocacionadas para a obtenção de resultados intermédios, "ao identificar pontos fortes e pontos fracos, bem com oportunidades de desenvolvimento e constrangimentos, a avaliação externa oferece elementos para a construção ou para o aperfeiçoamento de planos de melhoria e de desenvolvimento de cada escola". Subsequentemente, assiste-se a uma tradução da gestão daqueles processos em resultados finais, fomentando "nas escolas uma interpelação sistemática sobre a qualidade das suas práticas e dos seus resultados", concorrendo, e simultâneo para "a regulação do funcionamento do sistema educativo" (Portugal, ME - IGE, 2009, p. 5).

Ocorre dizer, então, que estamos perante um esquema de "extração de contas", (Lima, 2011, p. 36). Neste caso, a escola, em exclusivo, passa a ser a principal unidade de análise - ou "unidade crítica" (Sá, 2009, p. 91) - de verificação dos índices de eficiência, eficácia e de qualidade do Sistema, segundo parâmetros e indicadores de análise alinhados com:

“b) Resultados escolares, em termos, designadamente, de taxa de sucesso, qualidade do mesmo e fluxos escolares;

c) Inserção no mercado de trabalho; [...];

j) Eficiência de organização e de gestão; [...];

n) Parcerias com entidades empresariais; [...]." (n. ${ }^{\circ} 3$, do art. ${ }^{\circ}{ }^{\circ} .^{\circ}$, da Lei n. ${ }^{\circ}$ 31/2002, de 20 de dezembro).

Além de resultar de uma arquitetura tecnocêntrica, consolidada num "[...] quadro de referência, conhecido pelas escolas, [que] visa definir detalhadamente o que se quer avaliar" (ME - IGE, 2009, p. 7), a estrutura dos objetivos da avaliação gera um efeito de instrumentalização dos referentes, domínios e dos indicadores de avaliação - enquanto constitutivos do referencial respetivo - sugestiva de uma alegada neutralidade tecnicista, alinhada com os efeitos dos "standards educacionais" (Thiesen, 2014, p. 192) dissipadores dos handicaps socioculturais da escola pública, já crónicos entre nós, tal como observa Jurjo Torres Santomé (2005, p. 89):

A linguagem dos indicadores encaminha-nos aos ideais da uniformidade, penalizando as diferenças e a diversidade, atacando a própria conceção daquilo que deve ser uma sociedade democrática. [...]. A linguagem da estandardização pretende justificar uma preocupação com as dimensões da equidade e justiça social, assegurando que todas as pessoas recebem a mesma educação, não obstante subjacente a este tipo de propostas se ocultar uma ou outra filosofia completamente diferente: uma ideologia que aposta num maior controlo e hierarquização do sistema educativo e que, além do mais, dá lugar a uma descontextualização no eixo da tomada de decisões. As resoluções sobre o ensino e a aprendizagem surgem à margem das escolas [...]. Aparecem os peritos, os técnicos da administração, usurpando funções e reduzindo as possibilidades de um governo democrático nas escolas.

Ou seja, no dizer de Monica Thuler (s.d., p. 175), ao "[...] medir a eficácia de uma escola, corre-se o risco de aprisionar a sua dinâmica numa perspetiva clássica e somativa, e o de acreditar que categorias pré-fabricadas possam captar uma realidade em constante movimento, que só existe no espaço de interação dos atores envolvidos".

Com efeito, ao concretizar a arquitetura do modelo de avaliação à feição tecnocrata de um "Grupo de Trabalho para a Avaliação das Escolas", o designado "efeito escola" com impacto na reificação do trabalho dos atores escolares, parece concretizar, ainda que não exclusivamente, uma "[...] avaliação para o mercado [que] surge associada a uma conceção de escola como empresa educativa, em que a grande finalidade é captar [ou satisfazer] clientes" (Sá, 2009, p. 91).

Nesse encalço, a "ideologia do management" (Afonso \& Estêvão, 1992, p. 91) tende a prevalecer na demanda prosseguida pela agenda neogerencialista da escola pública, cuja arquitetura do sistema de avaliação externa torna reféns os diretores e os coordenadores escolares no papel de gestores de organização e métodos organizacionais - da "ideologia e do discurso da qualidade" (Lima, 1994, p. 128) e da eficiência e eficácia do seu trabalho.

Eis o contributo da avaliação externa das escolas para o "movimento das escolas eficazes (effective school)" (Martins, 2014, p. 27), cujos resultados tendem a manifestar-se além do valor esperado, em que os atores escolares tendem a sofrer "pressão política exercida do topo para a base e a pressão dos alunos, exercida no sentido contrário, da base para o topo" (Macbeath, Meuret, Schratz \& Jakobsen, 2005, p. 155).

Num pressuposto de univocidade e absoluto consenso, o discurso dogmático sedimentado por tais prerrogativas tem vindo a produzir um efeito, quase imediato e, por vezes, até sedutor, da instrumentalização daqueles atores estrategicamente afetos a funções-chave, que permite à tutela ativar processos periféricos de controlo, muito particularmente, da ação dos professores, com o objetivo 
de registarem a manifestação e a evolução dos padrões de desempenho (cf. Likert, 1971). Para o efeito, a tutela impõe às periferias, desde setembro de 2009, um quadro de referentes através do qual espera habilitar todas as escolas a seguirem, mimeticamente, os fatores e domínios de avaliação instituídos e normalizadores dos padrões de performance escalonados numa escala de classificação, e respetivos descritivos, a que cada organização escolar deverá submeter-se (cf. Portugal, ME - IGE, 2009, p. 9), a que subjaz uma avaliação institucional performativa.

\section{Os contributos da hermenêutica do referencial técnico gestionário e a narrativa do management}

É na senda do referencial técnico gestionário que o contexto económico surge como uma dimensão importante ao nível do desenvolvimento e condicionamento dos processos de referencialização, que concorrem para a formatação dos sistemas ou modelos de avaliação e da própria compreensão que se faz da conceção e imagem da escola pública. E isto tende a ocorrer em função da consecução de uma certa utilidade económica dos sistemas produtivos e, decorrentemente, da educação, segundo um critério universal e hegemónico de qualidade, em que a avaliação tende a instituir-se como uma iniciativa externa com "caráter de imposição" que conta com facilitadores internos e, ao mesmo tempo, como "iniciativa interna com facilitadores externos” (Santos Guerra, 2002, p. 17).

Com efeito, o espectro normativo legal da avaliação externa, além de todo o discurso oficial que a acompanha, tende a reforçar o ideário de uma agenda educativa preocupada em tomar a educação como um mero requisito ou uma simples apropriação do sistema económico (cf. Ramalho, 2002).

Consequentemente, a aplicação do conceito de eficácia económica à performance de cada escola decorre, necessariamente, de uma perspetiva de sistema de inputs e outputs que fazem parte do processo de produção educacional, em que a avaliação tem a função de recolher e interpretar informação sobre a produtividade educativa (cf. Hoenack \& Monk, 1990). Congruentemente, assistese a um enquadramento da produtividade educativa na relação produtivista estabelecida entre os resultados, os processos e os recursos, a partir do qual se tende a outorgar um cada vez mais impositivo ethos competitivo às escolas (cf. Ferreira, 2009).

Assim, o referencial técnico gestionário apresenta uma capacidade acrescida para influenciar e condicionar os processos de referencialização da avaliação do desempenho dos atores escolares, simplesmente porque domina a sociedade, condiciona os nossos valores, a nossa forma de estar, de compreender e conceber as coisas e a própria estrutura social sustentada pela exacerbada crença no progresso material da sociedade. Pelo domínio dos interesses e valores económicos posse, troca e lucro -, este referencial sugere uma conceção mecanomórfica e econométrica das escolas, inserindo-as numa perfilhação económica, competitiva e mecanicista (cf. Bertrand \& Valois, 1994), conduzindo àquilo que José Alberto Correia (2000, p. 13) designa por "ideologia da modernização" e a "definição económica da educação", ou, dito de outro modo, perspetiva a escola como locus de performance económica.

Congruentemente, a avaliação feita aos comportamentos, desempenhos e respetivos resultados educacionais tende a ser predominantemente quantitativa, cuja divulgação dos resultados (produtos) surge como condição fundamental para a fundamentação das escolhas educacionais (Afonso, 1998) geridas a partir dos planos de melhoria centralmente impostos às escolas, em linha com o movimento da school improvement (Melo, 2005; Lima, 2008; Martins, 2014).

Os processos de referencialização, segundo o referencial técnico gestionário, passam, então, a estar integrados numa narrativa neogerencialista, olhando para a própria avaliação como uma espécie de mecanismo de racionalização técnica e económica instrumentalizado para a monitorização e controlo da realização efetiva de objetivos económicos, por parte das escolas, segundo uma lógica de controlo com base na prestação de contas do tipo management accontability (cf. House, 1993; Afonso, 1998; Paquay, 2004). Associa-se a este conjunto de pressupostos a ação escolar realizada em conformidade com uma "pressão pública das lógicas de mercado" (Ferreira, 2009, p. 3832), radicada na crescente "autoridade do mercado" (Estêvão, 1998, p. 233), com o recurso, cada vez mais dogmático, da profissionalização da gestão das escolas como forma de fomentar níveis de execução padronizáveis (cf., a propósito, Young, 2008). Eis, por um lado, a escola perspetivada na configuração de agência de gestão de comportamentos, de desempenhos e de performances produtivos, e, por outro, como locus de reprodução da racionalidade económica dominante (cf., a propósito, Apple, 1986). A isto equivale dizer que a escola e os seus atores são inseridos num sistema cultural do tipo convergente e integrador orientado para produzir e medir mais-valia. Tal pressuposto cultural dá forma à proposta interpretativa $\mathrm{e}$ compreensiva de um referencial técnico gestionário e respetiva narrativa que inserem a avaliação das escolas na lógica do "mercado educacional" (Dale, 1995, p. 137) ou do "quase mercado educativo" (Estêvão, 1998, p. 235).

Ao mesmo tempo, o mercado desenvolve estratégias (ou, sendo ele próprio, a estratégia) para tornar periféricas o que antes eram responsabilidades centrais (cf. Dale, 1995). Para o efeito, emergem, por exemplo, o "ranking de escolas" num verdadeiro exercício da public choice - de leitura redutora neo-liberal - (Pereira, n.d.), livre oferta, livre procura/escolha e livre concorrência.

Reportando este cenário de referencialização a uma influência direta para o funcionamento das organizações escolares, podemos tecer algumas considerações que particularizam "a forma de fazer as coisas" no seu interior e, ainda, em relação às exigências que lhe chegam do exterior. Uma dessas exigências, aliás, a mais signatária, refere-se à institucionalização da norma-padrão centralista transformada ou reproduzida na forma de padrão operacional periférico.

É neste quadro de análise que, aliás, podemos referir o ímpeto do ethos neoliberal do estilo de governação das recentes legislaturas, sendo 
[...] característico $[\ldots], \quad$ das políticas contemporâneas visando o acréscimo de competitividade, de diferenciação e especialização, de eficiência e eficácia, a referência à privatização. A este fenómeno - entendido aqui sobretudo como abrangendo todas as formas de contaminação das políticas públicas pelo ethos do mercado -, a educação não ficou alheia, instituindo-se até como uma das áreas de maior investimento das políticas neoliberais [...]. Do mesmo modo, a generalização da regulação do mercado educativo, a transformação do cidadão em consumidor com direito a escolher a escola da sua preferência, a 'parentocracia, a promoção do consumidor em modelo cívico, a reindividualização das relações sociais, a ênfase na capacidade empreendedora e criativa dos atores educativos, a refocalização na qualidade educativa orientada para a satisfação do cliente têm-se imposto como os traços mais distintivos da nova ideologia no campo da educação conduzindo, simultaneamente a um menosprezo do papel que as escolas detinham na socialização política dos jovens, à valorização da diferenciação pela aquisição de bens e serviços educativos e à mercantilização das relações educativas (Estêvão, 2001, p. 147, 148).

Esta orientação para o cliente sugere que os processos de legitimação dos pressupostos oriundos do referencial técnico gestionário encontram a sua legitimação na vontade e nas escolhas da sociedade civil mercadorizada (Estêvão, 1998). Aliás, as transformações que preconiza ao nível dos mecanismos de autonomização, administração e gestão das escolas são equacionadas e formatadas no sentido de desenvolver meios de prova da prática bem sucedida do management no interior das escolas posto ao serviço da escolha pública, obedecendo a um efeito de empresarialização da educação (cf. Correia, 2000).

Surgindo como indicador da reedição da ideologia neoliberal para a educação, a narrativa do management introduz referências de avaliação externa das escolas radicadas na agenda do controlo e verificação do potencial produtivo e economicamente viável da escola pública. Com efeito, os pressupostos desta narrativa orientam-se para a promoção de uma educação que se quer, não apenas como mero fator de competitividade económica, mas, ela própria, competitiva. Ou seja, a educação é perspetivada não como um investimento social estrutural, mas como um investimento económico cujos custos devem ser estratégica e racionalmente geridos, onde se inclui o recurso organizacional da escola pública, que pressupõe a racionalização e otimização como critérios fundamentais da gestão educativa, cujos níveis de eficiência e eficácia tendem a reportar-se, quase exclusivamente, a responsabilidades extraídas da periferia (cf. Ramalho, 2007).

\section{Conclusão}

As considerações tecidas em torno do referencial técnico gestionário e respetiva narrativa do management induzem-nos para uma proposta de articulação entre as respetivas referências e as correspondentes dimensões que, por seu lado resultam em referentes genéricos da avaliação de escolas. É através dessa articulação que sistematizamos e operamos com um exercício de compreensão do referencial técnico gestionário segundo a lógica de conceptualização de um "subtexto", um "contexto limitado" (cf. Figari, 1996, p. 74) ou, simplesmente, sob a forma de um "olhar conceptual privilegiado", de onde sobressaem as referências económicas e gestionárias da avaliação externa das escolas.

O nosso exercício de interpretação convoca-nos para uma abordagem da escola como organização produtiva aprovisionada com organização e métodos submetidos às regras mercantilistas conectadas a um sistema de finalidades económicas da escola pública.

Concludentemente, aferimos a uma arquitetura de referencialização cotejando diferentes linhas de análise e interpretação: $i$ ) conceitos e dimensões utilizáveis para a interpretação da avaliação externa das escolas: a escola perspetivada como contexto produtivo, racionalidade económica, a escola como empresa e a educação como mercado educacional; ii) principais referências constitutivas da avaliação externa das escolas: eficiência de gestão dos recursos educativos e eficácia produtiva e utilidade económica da escola, universalização dos interesses gestionários, extração de contas como estratégia de rendibilidade e de gestão de performances organizacionais, performance educacional orientada para o "cliente", tradução econométrica e quantitativa dos resultados da educação, adequação das finalidades educativas aos objetivos económicos, sujeição da educação ao critério da escolha pública; iii) funções da avaliação: referenciar a educação como domínio caracteristicamente económico/mercantil, introduzir mecanismos de gestão racional e otimizada das escolas, padronizar meios, processos e fatores de "produção escolar", certificar competências produtivas e económicas e comparar desempenhos organizacionais da escola pública com objetivos pré-ordenados.

\section{Agradecimentos}

Trabalho financiado pelo Unidade de I\&D do Instituto Politécnico de Viseu Centro de Estudos em Educação, Tecnologias e Saúde.

\section{Referencias}

Afonso, A. (1998). Políticas Educativas e Avaliação Educacional. Braga: IEP - CEEP, UM.

Afonso, A. \& Estêvão, C. (1992). A Avaliação no Contexto Organizacional da Empresa e da Escola: fragmentos de percursos comparados. Revista Portuguesa de Educação, (5), 81-103.

Apple, M. (1986). Ideología y Currículo. Madrid: Akal. Bertrand, Y. \& Valois, P. (1994). Paradigmas Educacionais: escola e sociedades. Lisboa: Instituto Piaget.

Correia, J. (2000). As Ideologias Educativas em Portugal nos Últimos 25 Anos. Lisboa: Edições Asa.

Dale, R. (1995). O Marketing do Mercado Educacional e a Polarização da Educação. In Pablo Gentili (org.). 
Pedagogia da Exclusão: crítica ao neoliberalismo em educação (pp. 137-168). Petrópolis: Vozes,

Estêvão, C. (1998). Redescobrir a Escola Privada Portuguesa como Organização. Braga: Universidade do Minho.

Estêvão, C. (2001). O público e o Privado em Educação: a providenciação pública do privado na educação portuguesa. In José Augusto Pacheco (org.). Políticas Educativas. O Neoliberalismo em Educação (pp. 135 157). Porto: Porto Editora.

Figari, G. (1996). Avaliar: que referencial? Porto: Porto Editora.

Ferreira, E. (2009). No Enredo da Avaliação: a governação democrática da escola numa vivência em teritório educativo de intervenção prioritária (TEIP). In Alfonso Barca Lozano, et al. (orgs.) In Atas do $X$ Congresso Galaico-Português de Psicopedagogia (pp. 3830-3844).

https://sigarra.up.pt/flup/pt/pub_geral.pub_view?pi_p ub_base_id=15002

Hoenack, S. \& Monk, D. (1990). Economic Aspects of Teacher Evaluation. In Jason Millman \& Linda Darling-Hammond (eds.). The New Handbook of Teacher Evaluation: assessing elementary and secondary school teachers (pp. 390-402). Newbury Park: Corwin Press.

House, H. (1993). Professional Evaluation: social impact and political consequences. London: Sage Publicatios.

Likert, R. (1971). Novos Padrões de Administração. São Paulo: Livraria Pioneira Editora.

Lima, J. (2008). Em busca da boa escola. Vila Nova de Gaia: Fundação Manuel Leão.

Lima, L. (1994). Modernização, racionalização e optimização: perspectivas neotaylorianas na organização e administração da educação. Cadernos de Ciências Sociais, 14, 119-139.

Lima, L. (2011). Conceções de Escola: para uma hermenêutica organizacional. In Licínio Lima (org.). Perspetivas de Análise Organizacional da Escola (pp. 15-57). Gaia: Fundação Manuel Leão.

Macbeath, J., Meuret, D., Schratz, M., \& Jakobsen, L. B. (2005). A História de Serena. Viajando Rumo a uma Escola Melhor. Porto: Asa.

Martins, L. (2014). A Autoavaliação das Escolas: procedimentos e perspetivas em análise. Tese de Doutoramento, Universidade Católica Portuguesa, Lisboa.

Melo, R. (2005). A avaliação da escola. Dissertação de mestrado em Ciências da Educação, Universidade Católica Portuguesa, Lisboa.

Paquay, L. (2004). L'Évaluation des Ensignantes: tensions et enjeux. Paris: L'Harmattan.

Portugal, Lei n. ${ }^{\circ}$ 31/2002, de 20 de dezembro - Aprova o sistema de educação e do ensino não superior. Diário Da República - I Série-A n. ${ }^{\circ}$ 294-20 de dezembro de 2002.

Pereira, P. (n.d.). A Teoria da Escolha Pública (public choice): uma abordagem neo-liberal? http://analisesocial.ics.ul.pt/documentos/1221841484 T5sAW2pw7Dh10FX8.pdf
Portugal, Ministério da Educação, Inspeção-Geral da Educação (2009). Avaliação Externa Das Escolas Referentes e instrumentos de trabalho. http://www.ige.minedu.pt/upload/AEE_2010/AEE_R eferentes.pdf

Ramalho, H. (2002). Economia, Trabalho e Educação. Millenium, 6(25), 183-200.

Ramalho, H. (2007). Avaliação das Políticas Educativas. ELO 15, pp. 129-138.

Sá, V. (2009). A (auto)avaliação das escolas: "virtudes" e "efeitos colaterais". Ensaio, 17(62), 87-108.

Santos Guerra, M. (2002). Entre bastidores: o lado oculto da organização escolar. Porto: Edições ASA.

Thiesen, J. (2014). Currículo e Gestão Escolar: territórios de autonomia colocados sob a mira dos standards educacionais. Currículo sem Fronteiras, 14(1), 192202.

http://www.curriculosemfronteiras.org/vol14iss1articl es/thiesen.pdf

Thuler, M. (n.d.). A Eficácia das Escolas Não se Mede: ela se constrói, negoceia-se, pratica-se e se vive. http://www.crmariocovas.sp.gov.br/pdf/ideias_30_p1 5-192_c.pdf

Torres Santomé, J. (2005). Novas Políticas de Vigilância e Recentralização do Poder e Controlo em Educação. In João Paraskeva (org.). Um Século de Estudos Curriculares (pp.85-96). Lisboa: Plátano Editora.

Young, M. (2008). Conhecimento e Currículo: do socioconstrutivismo ao realismo social na sociologia da educação. Porto: Porto Editora. 